\title{
LA-6393-MS
}

informal Report

UC-21

Reporting Date: June 1970 Issued: June 1976

\section{Comment on Energy Deposition in Laser-Heated Plasmas}

by

Dale B. Henderson

Michael A. Stroscio

\section{scientific laboratory}

of the University of California

los alamos, NeW MeXICO 87545

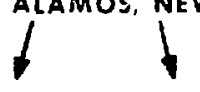

An Affirmative Artion/Equal Opportunity Employer 
This woik supported by the US Fnergy Research and Development Administration, Division of Laser Fusion.

Printed in the United States of America. Available from

National Technicel Information Service

U.S. Department of Commerce

5285 Port Royal Road

Springfield, VA 22161

Price: Printed Copy \$3.50 Microfiche $\$ 2.25$

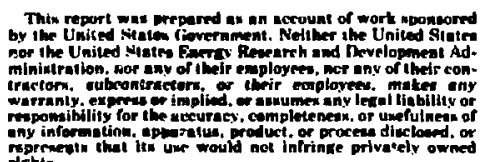

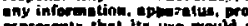

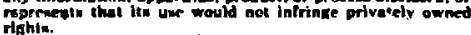


COMHENT ON

ENERGY DEPOSITION IN LASER-HEATED PLASMAS

by

Dale B. Henderson and Michael A. Scroscio

\section{ABSTRACT}

A simple connection between the $x$-ray spectrum and the number and energy distribution of suprathermal electrons in laser-heated plagmas has teen suggested by Brueckner. This relation is shown to depend sensitively on an inaccurate approximation to an integral occurring in the model.

Brueckner ${ }^{1}$ has calculated the number and energy distribucion of ouprathermal electrons produced in laser-heated plasmas using only the experimental $x$ ray spectrum. His derivation is, however, in error and his formulae should not be applied. In particular, conclusions to be drawn from his analysis applied to experimental examples are inconsistent with a correct analysis.

We begin with Eq. (5) of Ref, 1 (which is based on the unstated assumption that the collisional drag uniformiy dominates the other energy losses),

$$
\frac{d \epsilon_{\mathrm{rad}}}{d(\mathrm{hv})}=\frac{2}{3 \pi} \frac{\mathrm{e}^{2}}{\mathrm{hc}} \frac{\left\langle\mathrm{z}^{2}\right\rangle}{\mathrm{mc} \mathrm{c}^{2}\langle\mathrm{z}\rangle} \int_{\mathrm{hv}}^{E_{0}} \frac{\ln \Lambda_{\mathrm{rad}} \mathrm{d} E}{\ln \Lambda_{\mathrm{coll}}}
$$

where

$$
\begin{aligned}
& \Lambda_{\mathrm{coll}}=\left(3 / 2 \mathrm{e}^{3}\right)\left(\theta^{3} / \pi n_{\mathrm{e}}\right)^{1 / 2}, \text { and } \\
& \Lambda_{\mathrm{rad}}=\frac{\varepsilon^{1 / 2}+(\varepsilon-h \nu)^{1 / 2}}{\varepsilon^{1 / 2}-(\varepsilon-h v)^{1 / 2}} .
\end{aligned}
$$

At this point it was argued that $\ln \Lambda_{\text {coll }}$ and $\ln \Lambda_{\text {rad }}$ are slowly varyling functions. The approxination of Ind rad by a consiant, 2.0 , is insufficient. It

$$
\begin{aligned}
& \text { This seport wa' prepered as in acoount of wotk }
\end{aligned}
$$

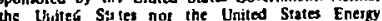

$$
\begin{aligned}
& \text { Reverch and Di relopment Administration, nol any or } \\
& \text { theis employeet, no: any of their contractors. } \\
& \text { subeoniscton, of theis employees. makes any } \\
& \text { wartanty, expres: of implied, of assumes any legal } \\
& \text { bibility or respor sbithy for the accurrcy. completenew }
\end{aligned}
$$

varifes frofi zero to infinity over the range of integration, as $h v / \varepsilon_{0}$ goes co zero. Also, the evaluation of $\ln \Lambda_{\text {coll }}$ was aumerically incerrect; it should have been 13.1 rather than 7.85 at $10 \mathrm{keV}$ and $10^{21} / \mathrm{cm}^{3}$.

Actually the Indicated Integration may be performed analytically. We have from Ref. I:

$\frac{d \varepsilon_{\text {rad }}}{d(h \nu)}=\frac{\lambda_{2}}{m c^{2}} \cdot \frac{1}{2} \int_{h \nu}^{50} \ln \frac{\epsilon^{1 / 2}+(E-h \nu)^{1 / 2}}{E^{1 / 2}-(\varepsilon-h \nu)^{1 / 2}} d \epsilon$,

where $i_{z}=\frac{4}{3 \pi} \frac{\mathrm{e}^{2}}{\hbar c} \frac{\left\langle z^{2}\right\rangle}{\langle z\rangle} \frac{1}{\ln \lambda_{\operatorname{col} I}}$.

Here we have only to change vartables to $x^{2}=$ (1 - hV/E) and to integrate by parts to obtain

$$
\begin{gathered}
\frac{\mathrm{d} \varepsilon_{\mathrm{rad}}}{\mathrm{d}(\mathrm{hv})}=\frac{\lambda_{\mathrm{z}}}{\mathrm{m \textrm {c } ^ { 2 }}} \cdot \frac{1}{2} . \\
{\left[\left(\varepsilon_{\mathrm{o}}-\frac{\mathrm{hv}}{2}\right) \ln \left[\frac{1+\left(1-\frac{\mathrm{hv}}{\varepsilon_{\mathrm{o}}}\right)^{1 / 2}}{1-\left(1-\frac{\mathrm{hv}}{\varepsilon_{\mathrm{o}}}\right)^{1 / 2}}\right]-\varepsilon_{\mathrm{o}}\left(1-\frac{\mathrm{hv}}{\varepsilon_{\mathrm{o}}}\right)\right.} \\
{\left[\frac{1 / 2}{}\right]}
\end{gathered}
$$


which replaces equation (6) of Ref. 1:

$$
\frac{\mathrm{d} \varepsilon_{\mathrm{rad}}}{\mathrm{d}(\mathrm{hv})}=\frac{\lambda_{z}}{\mathrm{mc}} \cdot\left[\left(\varepsilon_{0}-\mathrm{h \nu}\right)\right]
$$

We also note that in the limit of low energy, $h v \rightarrow 0$, ous result diverges (In the infrared catastrophe) while the original equation (6) is finite. In the linit of high energy, $h \nu \rightarrow \varepsilon_{o}$, our result becomes

$$
\operatorname{Lim}_{h v \rightarrow \varepsilon_{0}} \frac{d \varepsilon_{\mathrm{rad}}}{\mathrm{d}(\mathrm{nV})}=\frac{\lambda_{\mathrm{z}}}{\mathrm{mc}^{2}} \frac{2 \varepsilon_{\mathrm{o}}}{3}\left(1-\frac{\mathrm{h \nu}}{\varepsilon_{\mathrm{o}}}\right)^{3 / 2} \text {; that is, } 1 \mathrm{t}
$$

goes to zero faster than the original result. Thus, the approximation in Ref. 1. Is never a good functional form although it may coincidentally give reasonable numericai values for certain arguments. Not being a good functional form, it snould not be differentlated. With our resulc substituted into equation (?) of Ref. 1, the resulting

$$
\frac{d E_{\text {Yad }}}{d(h v)}=\int_{h v}^{\infty} n\left(\varepsilon_{0}\right) \frac{d \varepsilon_{\text {rad }}}{d(h v)} d \varepsilon_{0}
$$

cannot be differentlated to obtain the results reported in Eqs. (9), (10), and (11). That such aimple (non-integral) formulae may be derived is a consequence of the spectal kernel 1a Eq. (8) of Ref. 1. In particular, the number of fast electrons and their energy cannot be simply obtained from the experimental x-ray spectrum as stated in Ref. 1. The correct inversion to $n\left(\varepsilon_{0}\right)$ from experimental $d E_{\text {rad }} / d(h v)$ is not obvious and probably needs to be done with trial-and-error numerical integration. In any case, the values of $\mathrm{N}_{\text {fast }}$ and $E_{\text {fast }}$ obtalned through Eqs. (10) and (11) of kef. 1 should not be used.

\section{REFERENCES}

1. K. A. Brueckner, Phys. Rev. Lett. 36,677 (1976). 